\title{
Evaluation of endoscopic ultrasound fine-needle aspiration versus fine-needle biopsy and impact of rapid on-site evaluation for pancreatic masses
}

\section{(ㄷ)(우우}

\section{Authors}

Diogo T.H. de Moura ${ }^{1,2,3}$, Thomas R. McCarty ${ }^{1,2}$, Pichamol Jirapinyo ${ }^{1,2}$, Igor B. Ribeiro ${ }^{3}$, Kelly E. Hathorn ${ }^{1,2}$, Antonio Coutinho Madruga-Neto ${ }^{3}$, Linda S. Lee ${ }^{1,2}$, Christopher C. Thompson ${ }^{1,2}$

Institutions

1 Division of Gastroenterology, Hepatology and Endoscopy, Brigham and Women's Hospital, Boston Massachusetts, United States

2 Harvard Medical School, Boston, Massachusetts, United States

3 Gastroenterology Department, Hospital das Clínicas da Faculdade de Medicina da Universidade de São Paulo, SP, Brazil

submitted 9.10.2019

accepted after revision $\quad 6.2 .2020$

\section{Bibliography}

DOI https://doi.org/10.1055/a-1122-8674 |

Endoscopy International Open 2020; 08: E738-E747

(c) Georg Thieme Verlag KG Stuttgart · New York

eISSN 2196-9736

Corresponding author

Christopher C. Thompson, MD, MSc, Division of

Gastroenterology, Hepatology and Endoscopy, Brigham

and Women's Hospital, 75 Francis Street, Boston, MA

02115, USA

Fax: +1-617-264-6342

cthompson@hms.harvard.edu

A Appendix 1

Online content viewable at:

https://doi.org/10.1055/a-1122-8674

\section{ABSTRACT}

Background and study aims Endoscopic ultrasound (EUS)-guided fine needle aspiration (FNA) is traditionally considered a first-line strategy for diagnosing pancreatic lesions; however, given less than ideal accuracy rates, fineneedle biopsy (FNB) has been recently developed to yield histological tissue. The aim of this study was to compare diagnostic yield and safety between EUS-FNA and EUS-FNB in sampling of pancreatic masses.
Patients and methods This was a multicenter retrospective study to evaluate efficacy and safety of EUS-FNA and EUS-FNB for pancreatic lesions. Baseline characteristics including sensitivity, specificity, and accuracy, were evaluated. Rapid on-site evaluation (ROSE) diagnostic adequacy, cell-block accuracy, and adverse events were analyzed. Subgroup analyses comparing FNA versus FNB route of tissue acquisition and comparison between methods with or without ROSE were performed. Multivariable logistic regression was also performed.

Results A total of 574 patients ( $n=194$ FNA, $n=380$ FNB) were included. Overall sensitivity, specificity, and accuracy of FNB versus FNA were similar [ $89.09 \%$ versus $85.62 \%$; $P=$ $0.229)$, (98.04\% versus $96.88 \% ; P=0.387)$, and $90.29 \%$ versus $87.50 \% ; P=0.307)]$. Number of passes for ROSE adequacy and cell-block accuracy were comparable for FNA versus FNB [(3.06 \pm 1.62 versus $3.04 \pm 1.88 ; P=0.11)$ and $(3.08 \pm 1.63$ versus $3.35 \pm 2.02 ; P=0.137)]$. FNA + ROSE was superior to FNA alone regarding sensitivity and accuracy [91.96\% versus $70.83 \% ; P<0.001)$ and $(91.80 \%$ versus $80.28 \% ; P=0.020)]$. Sensitivity of FNB + ROSE and FNB alone were superior to FNA alone [(92.17\% versus $70.83 \%$; $P<$ $0.001)$ and $(87.44 \%$ versus $70.83 \% ; P<0.001)]$. There was no difference in sensitivity though improved accuracy between FNA+ROSE versus FNB alone [ $(91.96 \%$ versus $87.44 \% ; P=0.193)$ and $(91.80 \%$ versus $80.72 \% ; P=0.006)]$. FNB + ROSE was more accurate than FNA+ROSE (93.13\% versus $91.80 \% ; P=0.001)$. Multivariate analysis showed ROSE was a significant predictor of accuracy [OR 2.60 (95\% $\mathrm{Cl}, 1.41-4.79)]$. One adverse event occurred after FNB resulting in patient death.

Conclusion EUS-FNB allowed for more consistent cellblock evaluation as compared to EUS-FNA. EUS-FNA + ROSE was found to have a similar sensitivity to EUS-FNB alone suggesting a reduced need for ROSE as part of the standard algorithm of pancreatic sampling. While FNB alone produced similar diagnostic findings to EUS-FNA + ROSE, FNB + ROSE still was noted to increase diagnostic yield. This finding may favor a unique role for FNB + ROSE, suggesting it may be useful in cases when previous EUS-guided sampling may have been indeterminate. 


\section{Introduction}

Pancreatic cancer is the fourth leading cause of cancer-related death in Western countries with an overall 5 -year survival rate of $5 \%$ to $6 \%$ and a median survival of 3 to 5 months after diagnosis of metastatic disease. Accurate diagnosis of pancreatic lesions is crucial to ensure that proper treatment is provided and the optimum prognosis achieved [1-4].

Diagnosis of pancreatic lesions was significantly improved with application of endoscopic ultrasound (EUS). EUS-guided fine-needle aspiration (FNA) has been the mainstay for tissue acquisition for evaluation of pancreatic lesions since 1990s, with sensitivity varying from $88 \%$ to $100 \%$ and specificity of up to $100 \%$ [5-9]. Despite the success of EUS-FNA, the diagnostic sampling technique has several limitations. The most important limitation of FNA is that cytology specimens may be of limited value in certain disease entities for which diagnosis relies on tissue architecture or ancillary studies [3-5]. For example, cytological analysis alone may not distinguish inflammation from well-differentiated neoplasia because inflammation results in a reactive and regenerative process leading to cellular changes. In addition, certain conditions, such as lymphoma, neuroendocrine tumors, autoimmune pancreatitis, and stromal tumors, require histological specimens with preserved architecture, necessitating immunohistochemical (IHC) staining and histologic diagnosis [10-13]. Furthermore, EUS-FNA often requires multiple passes to obtain adequate tissue and rapid on-site evaluation (ROSE) for optimal yield, although it remains unclear to what extent ROSE impacts diagnostic accuracy [7, $14,15]$.

To overcome limitations associated with EUS-FNA cytology and improve diagnostic accuracy, a 19G trucut needle biopsy (EUS-TNB) was designed to procure larger amounts of tissue with conserved architecture, thus enabling histological analysis. Although EUS-TNB has shown greater diagnostic accuracy compared with EUS-FNA for submucosal lesions and lymphoma, and potentially required fewer needle passes for solid pancreatic neoplasms, this first generation fine-needle biopsy (FNB) device failed to demonstrate superiority over traditional FNA. Moreover, the technical failure rate was high, especially when TNB was attempted with an angulated scope position such as a transduodenal approach due to the stiffness of the device $[16,17]$. Consequently, more flexible second-generation core biopsy needles have been developed, and are being increasingly utilized for tissue acquisition - providing not just cytological aspirates but also histologic core samples.

These include reverse bevel needles, side-open needles, and fork-tip needles to collect core sample. These needles are available in several sizes including 19G, 20G, 21G, 22G, and 25G needles and enable approaches such as a transduodenal approach, which is important for lesions in the head and uncinate process of the pancreas [3-5,7]. Core tissue samples obtained with these newer FNB needles may improve diagnostic yield and obviate the need for ROSE; however, data is limited. A previous meta-analysis reported that EUS-FNB is a reliable diagnostic tool for solid pancreatic masses with sensitivity and specificity of $84 \%$ and $98 \%$, respectively [18]; however, high-quality studies comparing these second generation FNB needles with standard FNA needles have reached different conclusions [2, 5].

We therefore conducted this large multicenter study, to compare diagnostic yield and safety between EUS-FNA and EUS-FNB in sampling of pancreatic masses.

\section{Patients and methods}

\section{Material and methods}

This was a multi-center, retrospective study conducted at five hospitals in Massachusetts, United States (Brigham and Women's Hospital, Massachusetts General Hospital, Brigham and Women's Faulkner Hospital, Newton-Wellesley Hospital, and North Shore Medical Center) following the STAndards for the Reporting of Diagnostic accuracy studies (STARD) recommendations (Appendix 1). The study was approved by the Institutional Review Board from Partners Healthcare. All consecutive patients, age $\geq 18$ years, that had undergone EUS-guided tissue acquisition of pancreatic masses from January 2016 to January 2019 were identified from a shared prospective registered. Search terms included: endoscopic ultrasound and pancreatic mass or pancreatic lesion and fine needle aspiration or fine needle biopsy. This database contains information on patient demographics (i.e., sex, age, and comorbidities), lesion characteristics (i.e., location, size, heterogeneity, and echogenicity), and procedure details (i.e., route of tissue sampling, size and type of the needle, number of passes, diagnostic adequacy of cytological specimen on rapid on-site evaluation (ROSE) when it was available, and diagnostic adequacy on cell block and on slides examination). Additionally, the database contains information regarding patient follow-up, including adverse events (AEs), other diagnostic methods if performed, oncological treatment, and surgery.

\section{Procedural technique}

All EUS-guided tissue sampling procedures were performed with a linear array echoendoscope (Olympus GF-UCT180, Olympus, Center Valley, Pennsylvania, United States) under monitored anesthesia care by experienced endosonographers or by fellows under expert supervision. Several different needles were used during these period, including 19G, 22G, and 25G FNA needles (Expect, Boston Scientific Corporation, Natick, MA, USA or Echotip, Wilson-Cook Medical, Winston-Salem, North Carolina, United States or Beacon, Medtronic Corporation, Newton, Massachusetts, United States) and 19G, 20G, 21G, 22G, and 25G FNB needles (Acquire, Boston Scientific Corporation, Natick, Massachusetts, United States or SharkCore, Medtronic Corporation, Newton, Massachusetts, United States or ProCore, Cook Medical, Winston-Salem, North Carolina, United States). After the lesion was identified and punctured under EUS guidance, a general fanning technique was performed. Individual operator technique varied from each center, including stylet slow-pull technique and standard suction. 


\section{Rapid on-site evaluations (ROSE)}

ROSE, which may be used to check sample adequacy and establish a preliminary diagnosis using a rapid stain, was not available in all cases. In cases where ROSE was performed, FNA specimens were expressed onto slides and then smeared for onsite preparation. FNB specimens were prepared using the touch imprint technique. To accomplish this technique, the tissue surface was slighted pressed onto the slides prior to staining to reduce the creation of crushing artifacts. All slides were prepared using both wet-fixed (placed in $96 \%$ ethyl alcohol for Papanicolaou staining) and air-dried (in some cases stained with DiffQuik) techniques.

\section{FNA evaluation}

The samples obtained through EUS-FNA were transferred to three to 12 slides. Each smear was made with slight pressure to avoid crushing artifacts with half of the slides then placed immediately in the $96 \%$ ethyl alcohol solution and the others fixed in the air. When possible, part of the material was placed in formalin solution for the preparation of the cell-block. The specimen was subsequently sent to the pathology division, for processing and staining by Papanicolaou method (i. e., slides in alcohol solution), Diff-Quick Staining Protocol (i.e., air-dried slides), and hematoxylin and eosin stain (i.e., cell-block). After these processes, the cytological material was examined by experienced cytopathologists. IHC analysis was performed in selected cases when needed.

\section{FNB evaluation}

FNB samples were fixed in buffered formalin (10\% formalin) and dehydrated before being embedded in paraffin. The tissue was subsequently sliced into a $4-\mu \mathrm{m}$ to $6-\mu \mathrm{m}$ sections and stained with hematoxylin-eosin. In addition, in some cases, FNB specimens were prepared in slides using the touch imprint technique. The analyzes were performed by experienced pathologists. IHC analysis was performed in selected cases when needed.

\section{Outcome measures}

The primary outcome was the diagnostic yield [i.e., sensitivity, specificity, positive likelihood ratio $(L R+)$, negative likelihood ratio ( $L R-$ ), positive predictive value (PPV), negative predictive value (NPV), and accuracy] of EUS-FNA and EUS-FNB from cytologic or histologic analysis with and without IHC staining. Inconclusive specimen results were considered as non-neoplastic lesions as to not overestimate diagnostic yield. Secondary outcomes included the proportion of adequate cellularity for ROSE evaluation, median number of needle passes, diagnostic result from histologic (cell-block) and cytologic (slides) analysis, as well as AEs related to the procedure. Surgical resection pathology was considered the gold standard for comparison to determine diagnostic accuracy. However, because most patients did not undergo surgery due to benign findings or poor surgical candidacy, patient follow-up for at least 6 months was also considered as the reference standard.

\section{Statistical analysis}

Baseline patient characteristics and procedure characteristics were summarized as means \pm standard deviation for continuous data and frequencies and proportions for categorical data. As diagnostic tests were performed on two independent groups of patients, a bivariate model was used to compute the pooled sensitivity and specificity, and diagnostic accuracy. Two-sample t-tests for binomial proportions were used [19]. Continuous data were compared using the two-sample t-test or Wilcoxon rank-sum test and categorical data were compared using the Chi-square or Fisher's exact test as appropriate [20]. Statistical significance was defined as a $P<0.05$.

Subgroup analyses to compare diagnostic yield were performed based upon route of sampling. Additional analyses were also performed to identify the diagnostic yield of FNA alone, FNA with ROSE, FNB alone, and FNB with ROSE. From this data, sensitivity, specificity, PPV, NPV, +LR, -LR, and accuracy were compared to determine if ROSE was beneficial. In effort to identify factors associated with diagnostic performance between FNA and FNB needle types, a multivariable logistic regression was performed with adjustment for clinically significant univariate findings as well as age, gender, needle type, needle size, and application of ROSE and cell block on. Results of the regression analysis were expressed as beta-coefficient $(\beta)$ and odds ratio (OR). Statistical analyses were performed using the Stata 13.0 software package (Stata Corp LP, College Station, TX).

\section{Results}

\section{Baseline patient and lesion characteristics}

A total of 574 patients (308 male and 266 female) with a mean age of $60.85 \pm 12.81$ years old were enrolled in this study between January 2016 to January 2019. No significant difference was noted between FNA and FNB cohorts. Technical success was $100 \%$. Of the 574 patients, 194 underwent FNA and 380 FNB. Most of the lesions were located at the head of the pancreas $(n=248)$, followed by body $(n=141)$, tail $(n=109)$, uncinate $(n=42)$, and neck $(n=34)$. The most common route of sampling was via a transduodenal approach (49.45\%) followed by transgastric $(48.91 \%)$, with the remaining procedures requiring both transduodenal and transgastric approaches (1.64\%). Mean size of all lesions was $28.56 \pm 13.38 \mathrm{~mm}$ with no difference in sizes between FNA and FNB $(27.02 \pm 14.05 \mathrm{~mm}$ versus 29.29 $\pm 13.01 ; P=0.066)$. Complete baseline characteristics for all included patients as well as stratification by FNA or FNB cohort are demonstrated in $>$ Table 1 .

\section{Needle and sampling characteristics}

Multiple needle sizes were used in this study, including, 20G, 21G, 22G, and 25G. The latter two were more commonly utilized $(52.89 \%$ and $45.71 \%$, respectively). There was a significant difference in needle size between FNA and FNB cohorts $(P<0.001)$ with FNA relying primarily upon $25 \mathrm{G}$ and FNB with $22 \mathrm{G}$ needle. There was no significant difference in number of passes between lesions sampled with FNA and FNB (3.04 \pm 1.88 
- Table 1 Baseline patient characteristics, lesion details, and sampling characteristics.

\begin{tabular}{|c|c|c|c|c|}
\hline Results & Total & FNA & FNB & $P$ value \\
\hline \multicolumn{5}{|l|}{ Patient characteristics } \\
\hline No. of patients & 574 & 194 & 380 & \\
\hline Age (years) & $66.69(11.76)$ & $66.28(10.75)$ & $66.90(12.26)$ & 0.633 \\
\hline Gender & & & & 0.296 \\
\hline No. of males (\%) & $308(53.66 \%)$ & $110(56.70 \%)$ & $198(52.11 \%)$ & \\
\hline No. of females (\%) & $266(46.34 \%)$ & $84(43.30 \%)$ & $182(47.89 \%)$ & \\
\hline \multicolumn{4}{|l|}{ Pancreatic lesion site } & 0.819 \\
\hline Head & 248 & $85(43.81 \%)$ & $162(42.89 \%)$ & \\
\hline Neck & 34 & $9(4.64 \%)$ & $25(6.58 \%)$ & \\
\hline Body & 141 & $45(23.20 \%)$ & $96(25.26 \%)$ & \\
\hline Tail & 109 & $40(20.62 \%)$ & $69(18.16 \%)$ & \\
\hline Uncinate & 42 & $15(7.73 \%)$ & $27(7.11 \%)$ & \\
\hline Lesion size & $28.56(13.38)$ & $27.02(14.05)$ & $29.29(13.01)$ & 0.066 \\
\hline \multicolumn{4}{|l|}{ Diagnostic sample approach } & 0.097 \\
\hline Transgastric & $269(48.91 \%)$ & $88(48.35 \%)$ & $181(49.18 \%)$ & \\
\hline Tranduodenal & $272(49.45 \%)$ & $88(48.35 \%)$ & $184(50.00 \%)$ & \\
\hline Both transgastric and transduodenal & $9(1.64 \%)$ & $6(3.30 \%)$ & $3(0.82 \%)$ & \\
\hline \multicolumn{4}{|l|}{ Needle size } & $<0.001$ \\
\hline $20 \mathrm{~g}$ & $4(0.70 \%)$ & $0(0.00 \%)$ & $4(1.06 \%)$ & \\
\hline $21 \mathrm{~g}$ & $4(0.70 \%)$ & $0(0.00 \%)$ & $4(1.06 \%)$ & \\
\hline $22 \mathrm{~g}$ & $302(52.89 \%)$ & $66(34.20 \%)$ & $236(62.43 \%)$ & \\
\hline $25 \mathrm{~g}$ & $261(45.71 \%)$ & $127(65.80 \%)$ & $134(35.45 \%)$ & \\
\hline No of passes & $3.05(1.71)$ & $3.04(1.88)$ & $3.06(1.62)$ & 0.11 \\
\hline \multicolumn{4}{|l|}{ No. of samples with ROSE } & $<0.001$ \\
\hline Yes & $251(43.88 \%)$ & $122(62.89 \%)$ & $129(34.13 \%)$ & \\
\hline No & $321(56.12 \%)$ & $72(37.11 \%)$ & $249(65.87 \%)$ & \\
\hline \multicolumn{4}{|l|}{ Adequate sample for ROSE } & 0.914 \\
\hline Yes & $237(94.42 \%)$ & $115(94.26 \%)$ & $122(94.57 \%)$ & \\
\hline No & $14(5.38 \%)$ & $7(5.74 \%)$ & $7(5.43 \%$ & \\
\hline No. of passes for ROSE adequacy & $3.32(1.82)$ & $3.17(1.80)$ & $3.46(1.84)$ & 0.211 \\
\hline \multicolumn{4}{|l|}{ No. of samples with cell block } & $<0.001$ \\
\hline Yes & $511(89.02 \%)$ & $156(80.41 \%)$ & $355(93.42 \%)$ & \\
\hline No & $63(10.98 \%)$ & $38(19.59 \%)$ & $25(6.58 \%)$ & \\
\hline No. of passes for cell block diagnosis & $3.21( \pm 1.87)$ & $3.35(2.02)$ & $3.08(1.63)$ & 0.137 \\
\hline
\end{tabular}




\begin{tabular}{|c|c|c|c|c|}
\hline Diagnostic test characteristics & Total & FNA & FNB & $P$ value \\
\hline Sensitivity & $\begin{array}{l}87.96 \% \\
(95 \% \mathrm{Cl}, 84.74 \text { to } 90.71)\end{array}$ & $\begin{array}{l}85.62 \% \\
(95 \% \mathrm{Cl}, 79.22 \text { to } 90.66)\end{array}$ & $\begin{array}{l}89.09 \% \\
(95 \% \mathrm{Cl}, 85.22 \text { to } 92.24)\end{array}$ & 0.229 \\
\hline Specificity & $\begin{array}{l}97.59 \% \\
\text { (95\% Cl, } 91.57 \text { to } 99.71 \text { ) }\end{array}$ & $\begin{array}{l}96.88 \% \\
(95 \% \mathrm{Cl}, 83.78 \text { to } 99.92)\end{array}$ & $\begin{array}{l}98.04 \% \\
(95 \% \mathrm{Cl}, 89.55 \text { to } 99.95)\end{array}$ & 0.387 \\
\hline Positive likelihood ratio & $\begin{array}{l}36.50 \\
(95 \% \mathrm{Cl}, 9.28 \text { to } 143.58)\end{array}$ & $\begin{array}{l}27.40 \\
(95 \% \mathrm{Cl}, 3.98 \text { to } 188.81)\end{array}$ & $\begin{array}{l}45.44 \\
(95 \% \mathrm{Cl}, 6.52 \text { to } 316.51)\end{array}$ & 0.714 \\
\hline Negative likelihood ratio & $\begin{array}{l}0.12 \\
(95 \% \mathrm{Cl}, 0.10 \text { to } 0.16)\end{array}$ & $\begin{array}{l}0.15 \\
(95 \% \mathrm{Cl}, 0.10 \text { to } 0.22)\end{array}$ & $\begin{array}{l}0.11 \\
(95 \% \mathrm{Cl}, 0.08 \text { to } 0.15)\end{array}$ & 0.253 \\
\hline Positive predictive value & $\begin{array}{l}99.54 \% \\
\text { (95\% Cl, } 98.21 \text { to } 99.88)\end{array}$ & $\begin{array}{l}99.28 \% \\
\text { (95\% Cl, } 95.21 \text { to } 99.89)\end{array}$ & $\begin{array}{l}99.66 \% \\
(95 \% \mathrm{Cl}, 97.69 \text { to } 99.95)\end{array}$ & 0.529 \\
\hline Negative predictive value & $\begin{array}{l}57.86 \% \\
(95 \% \mathrm{Cl}, 51.88 \text { to } 63.61)\end{array}$ & $\begin{array}{l}57.41 \% \\
(95 \% \mathrm{Cl}, 47.88 \text { to } 66.41)\end{array}$ & $\begin{array}{l}58.14 \% \\
(95 \% \mathrm{Cl}, 50.44 \text { to } 65.46)\end{array}$ & 0.867 \\
\hline Accuracy & $\begin{array}{l}89.35 \% \\
(95 \% \mathrm{Cl}, 86.54 \text { to } 91.76)\end{array}$ & $\begin{array}{l}87.50 \% \\
(95 \% \mathrm{Cl}, 81.97 \text { to } 91.82)\end{array}$ & $\begin{array}{l}90.29 \% \\
(95 \% \mathrm{Cl}, 86.86 \text { to } 93.07)\end{array}$ & 0.307 \\
\hline Serious adverse events & $1(0.17)$ & $0(0.00)$ & $1(0.26)$ & 0.821 \\
\hline
\end{tabular}

versus $3.06 \pm 1.62 ; P=0.110$ ). The majority of patients did not have ROSE performed (56.12\%). ROSE was more commonly performed among FNA samples compared to FNB (62.89\% versus $34.13 \% ; P<0.001)$. Among patients having ROSE, sample adequacy for ROSE as well as number of passes was not significantly different [(FNA $94.26 \%$ versus FNB $94.57 \%, P=0.914$ ) and (FNA $3.17 \pm 1.80$ versus FNB $3.46 \pm 1.84 ; P=0.211$ ), respectively]. Cell-block analysis was more common among FNB lesions $(93.42 \%$ versus $80.41 \%$; $P<0.001)$ with a comparable number of passes required to achieve a conclusive diagnosis (FNA $3.33 \pm 2.02$ versus $3.08 \pm 1.63, P=0.137$ ). Further sampling characteristics are illustrated in $\triangleright$ Table 1 .

\section{Comparison of diagnostic characteristics}

Overall sensitivity, specificity, and accuracy of FNA and FNB for pancreatic lesions was $87.96 \%(95 \% \mathrm{Cl}, 84.74$ to 90.71$)$, $97.59 \%(95 \% \mathrm{Cl}, 91.57$ to 99.71$)$, and $89.35 \%(95 \% \mathrm{Cl}, 86.54$ to 91.76$)$. Compared to FNA, FNB resulted in comparable sensitivity [ $85.62 \%(95 \% \mathrm{Cl}, 79.22$ to 90.66$)$ versus $89.09 \%(95 \% \mathrm{Cl}$, 85.22 to 92.24$) ; P=0.229]$ and similar specificity [ $96.88 \%$ ( $95 \%$ $\mathrm{Cl}, 83.78$ to 99.92$)$ versus $98.04 \%(95 \% \mathrm{Cl}, 89.55$ to 99.95$) ; P=$ $0.387]$. Accuracy was not different for FNA as compared to FNB [ $87.50 \%(95 \% \mathrm{Cl}, 81.97$ to 91.82$)$ versus $90.29 \%(95 \% \mathrm{Cl}, 86.86$ to 93.07), $P=0.307]$. PPV and NPV were also similar for FNA versus FNB [( $99.28 \%(95 \% \mathrm{Cl}, 95.21$ to 99.89$)$ versus $99.66 \%$ (95\% $\mathrm{Cl}, 97.69$ to 99.95$), P=0.529)]$ and $[(57.41 \%(95 \% \mathrm{Cl}, 47.88$ to $66.41)$ versus $58.14 \%(95 \% \mathrm{Cl}, 50.44$ to 65.46$), P=0.867]$, respectively]. One patient with underlying pancreatitis and a suspected neuroendocrine tumor underwent EUS-FNB and her clinical condition worsened after the procedure. This patient died 5 days after tissue sampling due to worsening pancreatitis. Complete diagnostic test characteristics are shown in $>$ Table 2 .

\section{Subgroup analyses}

A subgroup analysis was also performed for lesion with subsequent surgical resection to confirm the diagnosis. A total of 156 patients (FNA: $n=56$ vs FNB: $n=100$ ) had confirmatory pathology via autopsy or surgical pathology. There was no difference in sensitivity [FNA: $87.27 \%(95 \% \mathrm{Cl}, 75.52$ to 94.73$)$ versus FNB: $85.71 \%(95 \% \mathrm{Cl}, 77.19$ to 91.96$), P=0.785]$ though FNB was associated with a higher specificity [FNA: $0.00 \%(95 \%$ $\mathrm{Cl}, 0.00$ to 97.50$)$ versus $\mathrm{FNB}: 100.00 \%(95 \% \mathrm{Cl}, 15.81$ to $100.00 \%) ; P<0.001]$. There was no difference in diagnostic accuracy between FNA versus FNB for patients with confirmed surgical pathology [FNA: $85.71 \%(95 \% \mathrm{Cl}, 73.78$ to 93.62$)$ versus FNB: $86.00 \%(95 \% \mathrm{Cl}, 77.63$ to $92.13 \%) ; P=0.960$ ].

\section{Comparison based on EUS-tissue sampling}

A comparison between FNA and FNB based on EUS-tissue sampling access was also performed. This analysis showed no difference in accuracy between needles based on transgastric or transduodenal approaches $(P>0.05)$. The results of the subgroup analysis are shown in $>$ Table 3 .

\section{Diagnostic yield with and without ROSE}

A comparison between methods with and without ROSE was also performed. Overall, FNB with ROSE presented the higher sensitivity, specificity, and accuracy compared to other variables. FNA with ROSE was superior to FNA alone regarding sensitivity and accuracy [91.96\% $(95 \% \mathrm{Cl}, 85.29$ to 96.26$)$ and $91.80 \%(95 \% \mathrm{Cl}, 85.44$ to 96.00$)$ versus $70.83 \%(95 \% \mathrm{Cl}$, 55.94 to 83.05$)$ and $80.28 \%(95 \% \mathrm{Cl}, 69.14$ to 88.78$)$; $P<$ 0.05]. Regarding sensitivity, both FNB and FNB with ROSE were superior to FNA alone $[87.44 \%(95 \% \mathrm{Cl}, 82.26$ to 91.56), $92.17 \%$ (95\% Cl, 85.66 to 96.36 ) versus $70.83 \%$ (95\% Cl, 55.94 to 83.05); $P<0.05)]$. FNB with ROSE presented higher 
- Table 3 Comparison between FNA and FNB based on EUS-tissue sampling access.

\begin{tabular}{|c|c|c|c|c|}
\hline Transgastric access & Total & FNA & FNB & $P$ value \\
\hline Sensitivity & $\begin{array}{l}85.40 \% \\
(95 \% \mathrm{Cl}, 80.11 \text { to } 89.73)\end{array}$ & $\begin{array}{l}84.29 \% \\
(95 \% \mathrm{Cl}, 73.62 \text { to } 91.89)\end{array}$ & $\begin{array}{l}87.01 \% \\
(95 \% \mathrm{Cl}, 80.66 \text { to } 91.88)\end{array}$ & 0.546 \\
\hline Specificity & $\begin{array}{l}97.78 \% \\
(95 \% \mathrm{Cl}, 88.23 \text { to } 99.94)\end{array}$ & $\begin{array}{l}100.00 \% \\
(95 \% \mathrm{Cl}, 81.47 \text { to } 100.00)\end{array}$ & $\begin{array}{l}96.30 \% \\
(95 \% \mathrm{Cl}, 81.03 \text { to } 99.91)\end{array}$ & 0.977 \\
\hline Positive likelihood ratio & $\begin{array}{l}38.43 \\
(95 \% \mathrm{Cl}, 5.53 \text { to } 267.11)\end{array}$ & NA & $\begin{array}{l}23.49 \\
(95 \% \mathrm{Cl}, 3.43 \text { to } 160.94)\end{array}$ & NA \\
\hline Negative likelihood ratio & $\begin{array}{l}0.15 \\
(95 \% \mathrm{Cl}, 0.11 \text { to } 0.21)\end{array}$ & $\begin{array}{l}0.16 \\
(95 \% \mathrm{Cl}, 0.09 \text { to } 0.27)\end{array}$ & $\begin{array}{l}0.13 \\
(95 \% \mathrm{Cl}, 0.09 \text { to } 0.20)\end{array}$ & 0.951 \\
\hline Positive predictive value & $\begin{array}{l}99.48 \% \\
(95 \% \mathrm{Cl}, 96.52 \text { to } 99.93)\end{array}$ & $100.00 \%$ & $\begin{array}{l}99.26 \% \\
(95 \% \mathrm{Cl}, 95.14 \text { to } 99.89)\end{array}$ & 0.419 \\
\hline Negative predictive value & $\begin{array}{l}57.14 \% \\
(95 \% \mathrm{Cl}, 49.23 \text { to } 64.70)\end{array}$ & $\begin{array}{l}62.07 \% \\
(95 \% \mathrm{Cl}, 48.75 \text { to } 73.79)\end{array}$ & $\begin{array}{l}56.52 \% \\
(95 \% \mathrm{Cl}, 46.18 \text { to } 66.33)\end{array}$ & 0.387 \\
\hline Accuracy & $\begin{array}{l}87.45 \% \\
(95 \% \mathrm{Cl}, 82.91 \text { to } 91.15)\end{array}$ & $\begin{array}{l}87.50 \% \\
(95 \% \mathrm{Cl}, 78.73 \text { to } 93.59)\end{array}$ & $\begin{array}{l}88.40 \% \\
(95 \% \mathrm{Cl}, 82.81 \text { to } 92.67)\end{array}$ & 0.831 \\
\hline \multicolumn{5}{|l|}{ Transduodenal access } \\
\hline Sensitivity & $\begin{array}{l}89.12 \% \\
(95 \% \mathrm{Cl}, 84.471 \text { to } 92.77)\end{array}$ & $\begin{array}{l}85.71 \% \\
(95 \% \mathrm{Cl}, 75.87 \text { to } 92.65)\end{array}$ & $\begin{array}{l}90.74 \% \\
(95 \% \mathrm{Cl}, 85.19 \text { to } 94.72)\end{array}$ & 0.214 \\
\hline Specificity & $\begin{array}{l}96.97 \% \\
(95 \% \mathrm{Cl}, 84.24 \text { to } 99.92)\end{array}$ & $\begin{array}{l}90.91 \% \\
(95 \% \mathrm{Cl}, 58.72 \text { to } 99.77)\end{array}$ & $\begin{array}{l}100.00 \% \\
(95 \% \mathrm{Cl}, 84.56 \text { to } 100.00)\end{array}$ & 0.943 \\
\hline Positive likelihood ratio & $\begin{array}{l}29.41 \\
(95 \% \mathrm{Cl}, 4.27 \text { to } 202.74)\end{array}$ & $\begin{array}{l}9.43 \\
(95 \% \mathrm{Cl}, 1.45 \text { to } 61.24)\end{array}$ & NA & NA \\
\hline Negative likelihood ratio & $\begin{array}{l}0.11 \\
(95 \% \mathrm{Cl}, 0.08 \text { to } 0.16)\end{array}$ & $\begin{array}{l}0.16 \\
(95 \% \mathrm{Cl}, 0.09 \text { to } 0.28)\end{array}$ & $\begin{array}{l}0.09 \\
(95 \% \mathrm{Cl}, 0.106 \text { to } 0.15)\end{array}$ & 0.482 \\
\hline Positive predictive value & $\begin{array}{l}99.53 \% \\
(95 \% \mathrm{Cl}, 96.87 \text { to } 99.93)\end{array}$ & $\begin{array}{l}98.51 \% \\
(95 \% \mathrm{Cl}, 91.04 \text { to } 99.77)\end{array}$ & $100.00 \%$ & 0.991 \\
\hline Negative predictive value & $\begin{array}{l}55.17 \% \\
(95 \% \mathrm{Cl}, 46.00 \text { to } 64.00)\end{array}$ & $\begin{array}{l}47.62 \% \\
(95 \% \mathrm{Cl}, 33.77 \text { to } 61.84)\end{array}$ & $\begin{array}{l}59.46 \% \\
(95 \% \mathrm{Cl}, 47.53 \text { to } 70.37)\end{array}$ & 0.902 \\
\hline Accuracy & $\begin{array}{l}90.07 \% \\
(95 \% \mathrm{Cl}, 85.89 \text { to } 93.36)\end{array}$ & $\begin{array}{l}86.36 \% \\
(95 \% \mathrm{Cl}, 77.39 \text { to } 92.75)\end{array}$ & $\begin{array}{l}91.85 \% \\
(95 \% \mathrm{Cl}, 86.91 \text { to } 95.37)\end{array}$ & 0.157 \\
\hline
\end{tabular}

accuracy than FNB alone [93.13 (95\% Cl, 87.36 to 96.81$)$ versus 80.72 ( $95 \% \mathrm{Cl}, 84.16$ to 92.40$) ; P=0.001$ ]. There was no difference in sensitivity though improved accuracy between FNA with ROSE versus FNB alone [(91.96\% versus $87.44 \% ; P=$ 0.193 ) and $(91.80 \%$ versus $80.72 \% ; P=0.006)$ ] ( $\triangleright$ Table 4 and - Table 5).

\section{Multivariate logistic regression}

Multivariate analysis was then performed controlling for age, gender, needle type, needle size, use of ROSE, and cell block assessment on diagnostic accuracy. Based upon the results of this multivariate logistic regression, ROSE was a significant predictor for better accuracy [OR $2.60(95 \% \mathrm{Cl}, 1.41$ to 4.79$) ; P=$ $0.002 ; \beta=0.96]$.

\section{Discussion}

The pathological diagnosis of a solid pancreatic lesion is important to ensure adequate management and optimize patient prognosis [11,13,21]. In this large, multi-center study, we compared EUS-FNA and EUS-FNB in many respects. Despite allowing a higher number of cell-block evaluations, EUS-FNB was comparable to EUS-FNA regarding accuracy, number of passes required for ROSE and cell-block evaluation, and safety profile. The addition of ROSE to EUS-FNA provided better accuracy as compared to EUS-FNA alone and EUS-FNB; however, sensitivity was not significantly different and EUS-FNB alone possessed a better specificity. The addition of ROSE to EUS-FNB provided even higher diagnostic yield suggesting that this may be helpful for select cases and those with prior failed diagnosis on EUSguided tissue sampling.

EUS-FNA of solid pancreatic lesions is a safe procedure, associated with high diagnostic accuracy, usually above $85 \%$, and 
- Table4 Comparison between methods with and without ROSE.

\begin{tabular}{|c|c|c|c|c|}
\hline Results & FNA alone & FNA with ROSE & FNB alone & FNB with ROSE \\
\hline Sensitivity & $\begin{array}{l}70.83 \% \\
(95 \% \mathrm{Cl}, 55.94 \text { to } 83.05)\end{array}$ & $\begin{array}{l}91.96 \% \\
(95 \% \mathrm{Cl}, 85.29 \text { to } 96.26)\end{array}$ & $\begin{array}{l}87.44 \% \\
(95 \% \mathrm{Cl}, 82.26 \text { to } 91.56)\end{array}$ & $\begin{array}{l}92.17 \% \\
(95 \% \mathrm{Cl}, 85.66 \text { to } 96.36)\end{array}$ \\
\hline Specificity & $\begin{array}{l}100.00 \% \\
(95 \% \mathrm{Cl}, 85.18 \text { to } 100)\end{array}$ & $\begin{array}{l}90.00 \% \\
(95 \% \mathrm{Cl}, 55.50 \text { to } 99.75)\end{array}$ & $\begin{array}{l}97.06 \% \\
(95 \% \mathrm{Cl}, 84.67 \text { to } 99.93)\end{array}$ & $\begin{array}{l}100.00 \% \\
(95 \% \mathrm{Cl}, 79.41 \text { to } 100.00)\end{array}$ \\
\hline Positive Likelihood Ratio & NA & $\begin{array}{l}9.20 \\
\text { (95\% Cl, } 1.43 \text { to } 59.09 \text { ) }\end{array}$ & $\begin{array}{l}29.73 \\
(95 \% \mathrm{Cl}, 4.31 \text { to } 205.16)\end{array}$ & NA \\
\hline Negative Likelihood Ratio & $\begin{array}{l}0.29 \\
(95 \% \mathrm{Cl}, 0.19 \text { to } 0.45)\end{array}$ & $\begin{array}{l}0.09 \\
(95 \% \mathrm{Cl}, 0.05 \text { to } 0.17)\end{array}$ & $\begin{array}{l}0.13 \\
(95 \% \mathrm{Cl}, 0.09 \text { to } 0.18)\end{array}$ & $\begin{array}{l}0.08 \\
(95 \% \mathrm{Cl}, 0.04 \text { to } 0.15)\end{array}$ \\
\hline Positive Predictive Value & $100.00 \%$ & $\begin{array}{l}99.04 \% \\
(95 \% \mathrm{Cl}, 94.13 \text { to } 99.85)\end{array}$ & $\begin{array}{l}99.47 \% \\
(95 \% \mathrm{Cl}, 96.46 \text { to } 99.92)\end{array}$ & $100.00 \%$ \\
\hline Negative Predictive Value & $\begin{array}{l}62.16 \% \\
(95 \% \mathrm{Cl}, 51.39 \text { to } 71.86)\end{array}$ & $\begin{array}{l}50.00 \% \\
(95 \% \mathrm{Cl}, 34.08 \text { to } 65.92)\end{array}$ & $\begin{array}{l}55.00 \% \\
(95 \% \mathrm{Cl}, 46.09 \text { to } 63.60)\end{array}$ & $\begin{array}{l}64.00 \% \\
(95 \% \mathrm{Cl}, 48.780 \text { to } 76.90)\end{array}$ \\
\hline Accuracy & $\begin{array}{l}80.28 \% \\
(95 \% \mathrm{Cl}, 69.14 \text { to } 88.78)\end{array}$ & $\begin{array}{l}91.80 \% \\
(95 \% \mathrm{Cl}, 85.44 \text { to } 96.00)\end{array}$ & $\begin{array}{l}80.72 \% \\
(95 \% \mathrm{Cl}, 84.16 \text { to } 92.40)\end{array}$ & $\begin{array}{l}93.13 \% \\
(95 \% \mathrm{Cl}, 87.36 \text { to } 96.81)\end{array}$ \\
\hline
\end{tabular}

FNA, fine-needle aspiration; FNB, fine-needle biopsy; ROSE, rapid one-site evaluation

- Table 5 Statistical analyses between methods with and without ROSE.

\begin{tabular}{|c|c|c|c|c|c|c|}
\hline & $\begin{array}{l}\text { FNA vs FNA+ } \\
\text { ROSE } \\
\text { (Pvalue) }\end{array}$ & $\begin{array}{l}\text { FNA vs FNB } \\
\text { (Pvalue) }\end{array}$ & $\begin{array}{l}\text { FNA vs FNB + } \\
\text { ROSE } \\
\text { (Pvalue) }\end{array}$ & $\begin{array}{l}\text { FNA + ROSE } \\
\text { vs FNB } \\
\text { (Pvalue) }\end{array}$ & $\begin{array}{l}\text { FNA + ROSE } \\
\text { vs FNB + ROSE } \\
\text { (P value) }\end{array}$ & $\begin{array}{l}\text { FNB vs FNB + } \\
\text { ROSE } \\
\text { (Pvalue) }\end{array}$ \\
\hline Sensitivity & $<0.001$ & $<0.001$ & $<0.001$ & 0.193 & 0.951 & 0.161 \\
\hline Specificity & 0.006 & 0.145 & NA & 0.004 & $<0.001$ & 0.048 \\
\hline Positive Likelihood Ratio & NA & NA & NA & $<0.001$ & NA & NA \\
\hline Negative Likelihood Ratio & 0.741 & 0.770 & 0.717 & 0.916 & 0.978 & 0.890 \\
\hline Positive Predictive Value & 0.409 & 0.547 & NA & 0.634 & 0.262 & 0.405 \\
\hline Negative Predictive Value & 0.103 & 0.284 & 0.796 & 0.365 & 0.025 & 0.091 \\
\hline Accuracy & 0.020 & 0.934 & 0.006 & 0.006 & 0.689 & 0.001 \\
\hline
\end{tabular}

typically better when ROSE is available [6-8]. However, the diagnostic accuracy of EUS-FNA with cytology is insufficient to verify cellular arrangement and tissue architecture. The limitation in achieving diagnosis using EUS-FNA is the pauci-cellular nature of the aspirate with a significant proportion of the collected tissue being distorted or consumed during automated processing and sectioning $[17,22]$. Procurement of histological samples that yield an adequate amount of tissue suitable for IHC staining is pivotal for personalized management of some lesions, such as metastatic lesions or gastrointestinal stromal tumors (GIST), and other uncommon lesions [12,13,21,22]. In our study, cell-block analysis was possible in $80.41 \%$ of patients after FNA and in $93.42 \%$ after FNB $(P<0.001)$. Our results are similar to a previous systematic review and meta-analysis including eight randomized controlled trials (RCTs) that compared these techniques [5].

In our study, technical success was reported in all patients, similar to several studies evaluating FNB needles $[3,14,23$,
24]. These results demonstrate that FNB can be easily performed in any location, unlike from the first generation FNB device (Tru-cut) [25]. Additionally, to confirm this finding we performed a subgroup analysis based on route of tissue sampling. We compared FNA and FNB performed via a transgastric and transduodenal route and showed no difference in accuracy between the two needle types [transgastric (FNA: $87.50 \%$ versus FNB: $88.40 \% ; P=0.831$ ) and transduodenal (FNA: $86.36 \%$ versus FNB: $91.85 \% ; P=0.157)$ ].

Most studies comparing FNA and FNB have demonstrated that these methods are comparable in terms of diagnostic accuracy, AEs, and technical success. However, FNB typically requires fewer needle passes to achieve adequate sampling for ROSE and cell-block $[3,5,24,26,27]$. A lower number of passes may be translated into shorter procedure time, less risk of adverse events, and more operational efficiency for both endoscopy and cytopathology units. However, unlike most previous studies, in our analysis, the number of passes required to 
achieve sample for ROSE (FNA: $3.04 \pm 1.88$, FNB: $3.06 \pm 1.62$ ) and cell-block (FNA: $3.35 \pm 2.02$, FNB: $3.08 \pm 1.63$ ) were similar between both techniques $(P>0.05)$.

The difference between our results and other studies may be due to the fact that ROSE is not widely used at all institutions included in this multi-center study. The fact that ROSE did not result in a lower number of needle passes, may have contributed to the overall higher tissue yield in the ROSE group. In our study, the majority of cases were performed without ROSE. Similar to our study, Bang et al. also showed no significant difference in mean number of passes required to establish a diagnosis in a RCT [28]. Nevertheless, our study illustrated FNB enables the diagnostic yield of more than $90 \%$ for cell-block assessment (FNA: $80.41 \%$ vs FNB: $93.42 \%, P<0.001$ ), showing that this technique may eliminate the need for ROSE.

Uniquely, in our study we compared both types of needles with and without ROSE. EUS-FNA with ROSE presented similar sensitivity and lower specificity to EUS-FNB alone. Similar to our results, a previous meta-analysis and additional retrospective study showed that EUS-FNB without ROSE provides a similar diagnostic yield than EUS-FNA with ROSE [7,29]. On subgroup analyses, we demonstrated that FNB with ROSE further increased the diagnostic yield (FNB with ROSE: 93.13\% versus FNB alone: $80.72 \%$ ), suggesting this may be useful in difficult cases, or in cases with failed diagnosis on prior EUS-tissue sampling. A systematic review including 10 FNB with ROSE studies and 13 FNB without ROSE studies did not show a significant difference between FNB with and without ROSE [30]. Presence of tissue cores was $86 \%$ in both groups. Mean sensitivity and specificity were $96 \%$ and $100 \%$ for the FNB with ROSE groups versus $86.6 \%$ and $100 \%$ in the FNB without ROSE group, respectively. Diagnostic adequacy and diagnostic accuracy were $86.5 \%$ and $85.5 \%$ for FNB with ROSE group versus $89,6 \%$ and $86.1 \%$ for FNB without ROSE group. To better understand the need for ROSE in FNB samples, a multi-center randomized non-inferiority trial is currently underway (FROSENOR) [31].

Unlike in most studies available in the literature, we analyzed the sensitivity, specificity, $+\mathrm{LR},-\mathrm{LR}, \mathrm{PPV}, \mathrm{NPV}$, and accuracy of EUS-FNA compared to EUS-FNB [3, 14, 23, 28, 32]. EUS-FNB had a better sensitivity (89.09\% versus $85.62 \%$ ), specificity $(98.04 \%$ versus $89.55 \%$ ), and accuracy (90.29\% versus $87.50 \%$ ) when compared to EUS-FNA; however, no statistical significance was found. Our results are similar to a prior RCT that evaluated the sensitivity, specificity, and accuracy of EUS-FNA versus EUS-FNB [4]. The sensitivity, specificity, and accuracy of FNA and FNB was $98.2 \%, 100 \%$, and $98.3 \%$ for FNA and $94.6 \%, 100 \%$, and $94.8 \%$ for FNB. The similar diagnostic yield between both techniques reported in our study is compatible with previous studies, including a systematic review and meta-analysis based on 8 RCTs [5].

These results may be related to the fact that both procedures have a high accuracy rate, and thus an even larger number of patients would be necessary to prove superiority of FNB. After these results, in an attempt to prove that FNB may be superior to FNA, a large randomized trial, including 408 patients, showed superiority favoring FNB. However, this study included both pancreatic ( $n=249$ patients) and non-pancreatic masses
( $n=159$ patients) [14]. Recently, another systematic review and meta-analysis [2] based on 11 relatively small randomized trials (three more studies than the previous meta-analysis [5]) showed that FNB was superior to FNA in sampling pancreatic masses [2]. Due to these heterogeneous results, we believe that more studies including a larger number of patients, such as our study are warranted to define the best modality in sampling pancreatic lesions.

Studies diverge on consideration of an inconclusive (non-diagnostic) result as benign or in exclude the result from the analysis. This fact is related to the heterogeneity of the previously results published in the literature $[4,6,14]$. When excluding inconclusive results, an increase in accuracy is observed. In this analysis we choose to be more rigorous and considered inconclusive results as benign lesions. As expected from sampling diagnostic modalities, the specificity and PPV were high in both techniques, showing that a positive result for a malignant lesion is very reliable. However, in both groups the sensitivity and NPV were low, and thus a negative result cannot exclude a neoplastic lesion. The $+L R$ measures how well a test diagnosis the lesion. The higher the $+L R$, the better the test performs in identifying the precise diagnosis. The $-L R$ of a test measures how well the test performs in excluding the disease. The lower the LR-, the better the test performs in excluding a disease. In our analysis, EUS-FNA and EUS-FNB showed similar +LR and -LR.

In our study, we also performed a multivariate analysis to find an association between several variables, including age, gender, needle type, needle size, use of ROSE, and cell block assessment on diagnostic accuracy. In our analysis, ROSE was the only independent predictor for better accuracy with an OR of 2.60. Different from our study, in a multivariable logistic regression of a series including both pancreatic and non-pancreatic solid lesions, FNB and lesion size were associated with the need to perform only one pass to achieve onsite diagnostic adequacy and were associated with procurement of diagnostically adequate histological specimens for offsite assessment [22].

The safety of EUS-tissue sampling is well established and few AEs are encountered in the literature. Severe adverse events are especially rare $[6,23,28,33]$. The safety profile of FNB was comparable to that of FNA, with only one AE encountered in the entire cohort - though this resulted in the patient's death. The AE occurred after an FNB procedure for suspected neuroendocrine tumor with active acute pancreatitis, which is a contraindication for the procedure. After the procedure, the patient clinically deteriorated, and passed away. We believe that this $\mathrm{AE}$ was not directly related to FNB as a technique, with any tissue sampling technique possessing the potential to cause this AE. Therefore, we do not recommend EUS-tissue sampling in patients with acute pancreatitis. No other AEs were reported. In the literature, several studies showed no AEs related to EUSFNA or EUS-FNB in the diagnosis of solid pancreatic lesions [3, $11,14]$.

Despite being the largest study to date to exclusively evaluate solid pancreatic lesions, we recognize there are some limitations to our study. This was a retrospective study with the inherent limitations expected with such a design, including potential selection bias, lack of randomization, and loss-to-fol- 
low-up. Although none of the patients with benign disease demonstrated disease progression at follow-up, we could not obtain further tissue results for ethical concerns. In addition, we included different needles sizes for FNA and FNB groups. However, a meta-analysis including just RCT did not show significant difference between different needles sizes [8]. We did not evaluate the needles regarding the various types of pancreatic masses. However, several studies have shown that FNB is associated with better results compared to FNA in several types of pancreatic lesions. Elhanafi et al showed that FNB should be considered when pancreatic adenocarcinoma genotyping is requested, especially for tumors smaller than $3 \mathrm{~cm}$ located in the head/neck of the pancreas [34]. In a retrospective study including 91 patients over a 13-year period evaluating FNA and FNB in neuroendocrine pancreatic tumors, FNB was found to improve diagnostic sensitivity and conferred additional information to cytological assessment [35]. In a RCT evaluating FNB needles in the diagnosis of type 1 auto-immune pancreatitis including 110 patients, the authors found that 36 patients could not be diagnosed with type 1 auto-immune pancreatitis without FNB results [36]. Procedural costs were not compared between the two cohorts in our study. However, recently a randomized trial showed that the strategy of EUS-FNB was cost saving compared to EUS-FNA over a wide range of cost and outcome probabilities [30].

\section{Conclusion}

In summary, EUS-FNB allowed for more consistent cell-block evaluation as compared to EUS-FNA, with similar number of passes required to achieve adequate sample. EUS-FNA with ROSE was found to have a similar sensitivity to EUS-FNB alone. Therefore, the similar sensitivity of EUS-FNA with ROSE compared to FNB alone suggests a reduced need for ROSE as part of the standard algorithm of pancreatic sampling. While FNB alone produced similar diagnostic findings to EUS-FNA with ROSE, FNB with ROSE still was noted to increase diagnostic yield. This finding may favor a unique role for ROSE, suggesting it may be useful in cases where previous EUS-guided sampling may have been indeterminate.

\section{Competing interests}

Dr. Thompson is a consultant for Medtronic, Boston Scientific, Olympus America, USGI medical, Fractyl, and Apollo Endosurgery.

\section{References}

[1] Hariharan D, Saied A, Kocher HM. Analysis of mortality rates for pancreatic cancer across the world. HPB (Oxford) 2008; 10: 58-62

[2] Li H, Li W, Zhou QY et al. Fine needle biopsy is superior to fine needle aspiration in endoscopic ultrasound guided sampling of pancreatic masses: A meta-analysis of randomized controlled trials. Medicine (Baltimore) 2018; 97: e0207

[3] Tian L, Tang AL, Zhang L et al. Evaluation of 22G fine-needle aspiration (FNA) versus fine-needle biopsy (FNB) for endoscopic ultrasound- guided sampling of pancreatic lesions: a prospective comparison study. Surg Endosc 2018; 32: 3533-3539

[4] Lee YN, Moon JH, Kim HK et al. Core biopsy needle versus standard aspiration needle for endoscopic ultrasound-guided sampling of solid pancreatic masses: a randomized parallel-group study. Endoscopy 2014; 46: 1056-1062

[5] Wang J, Zhao S, Chen Y et al. Endoscopic ultrasound guided fine needle aspiration versus endoscopic ultrasound guided fine needle biopsy in sampling pancreatic masses: A meta-analysis. Medicine (Baltimore) 2017; 96: e7452

[6] Moura DTH, de Moura EGH, Matuguma SE et al. EUS-FNA versus ERCP for tissue diagnosis of suspect malignant biliary strictures: a prospective comparative study. Endosc Int Open 2018; 6: E769-E777

[7] Khan MA, Grimm IS, Ali B et al. A meta-analysis of endoscopic ultrasound-fine-needle aspiration compared to endoscopic ultrasoundfine-needle biopsy: diagnostic yield and the value of onsite cytopathological assessment. Endosc Int Open 2017; 5: E363-E375

[8] Guedes HG, Moura DTH, Duarte RB et al. A comparison of the efficiency of $22 \mathrm{G}$ versus $25 \mathrm{G}$ needles in EUS-FNA for solid pancreatic mass assessment: A systematic review and meta-analysis. Clinics (Sao Paulo) 2018; 73: e261

[9] De Moura DTH, Moura EGH, Bernardo WM et al. Endoscopic retrograde cholangiopancreatography versus endoscopic ultrasound for tissue diagnosis of malignant biliary stricture: Systematic review and meta-analysis. Endosc Ultrasound 2018; 7: 10-19

[10] Ribeiro A, Vazquez-Sequeiros E, Wiersema LM et al. EUS-guided fine needle aspiration combined with flow cytometry and immunocytochemistry in the diagnosis of lymphoma. Gastrointest Endosc 2001; 53: $485-491$

[11] De Moura DTH, Rocha RSP, Jukemura J et al. A rare non-oncological pancreatic mass: eosinophilic pancreatitis diagnosis through EUSFNA. Endosc Int Open 2019; 7: E151-E154

[12] Brunaldi VO, Coronel M, Chacon DA et al. Subepithelial rectal gastrointestinal stromal tumor - the use of endoscopic ultrasound-guided fine needle aspiration to establish a definitive cytological diagnosis: a case report. J Med Case Rep 2017; 11: 59

[13] De Moura DTH, Coronel M, Chacon DA et al. Primary adenosquamous cell carcinoma of the pancreas: the use of endoscopic ultrasound guided - fine needle aspiration to establish a definitive cytologic diagnosis. Rev Gastroenterol Peru 2017; 37: 370-373

[14] Cheng B, Zhang Y, Chen Q et al. Analysis of fine-needle biopsy vs fineneedle aspiration in diagnosis of pancreatic and abdominal masses: a prospective, multicenter, randomized controlled trial. Clin Gastroenterol Hepatol 2018; 16: 1314-1321

[15] Wani S, Mullady D, Early DS et al. The clinical impact of immediate onsite cytopathology evaluation during endoscopic ultrasound-guided fine needle aspiration of pancreatic masses: a prospective multicenter randomized controlled trial. Am J Gastroenterol 2015; 110: 14291439

[16] Levy M]. Endoscopic ultrasound-guided trucut biopsy of the pancreas: prospects and problems. Pancreatology 2007; 7: 163-166

[17] Wittmann J, Kocjan G, Sgouros SN et al. Endoscopic ultrasound-guided tissue sampling by combined fine needle aspiration and trucut needle biopsy: a prospective study. Cytopathology 2006; 17: 27-33

[18] Yang Y, Li L, Qu C et al. Endoscopic ultrasound-guided fine needle core biopsy for the diagnosis of pancreatic malignant lesions: a systematic review and meta-analysis. Sci Rep 2016; 6: 22978

[19] Pepe MS. The statistical evaluation of medical tests for classification and prediction. Section 9.3. Oxford University Press; 2003

[20] Campbell I. Chi-squared and Fisher-Irwin tests of two-by-two tables with small sample recommendations. Stat Med 2007; 26: 3661-3675

[21] De Moura DTH, Coronel M, Ribeiro IB et al. The importance of endoscopic ultrasound fine-needle aspiration in the diagnosis of solid 
pseudopapillary tumor of the pancreas: two case reports. J Med Case Rep 2018; 12: 107

[22] Bang JY, Kirtane S, Krall K et al. In memoriam: Fine-needle aspiration, birth: Fine-needle biopsy: The changing trend in endoscopic ultrasound-guided tissue acquisition. Dig Endosc 2019; 31: 197-202

[23] Di Leo M, Crinò SF, Bernardoni L et al. EUS-guided core biopsies of pancreatic solid masses using a new fork-tip needle: A multicenter prospective study. Dig Liver Dis 2019; 51: 1275-1280

[24] Hucl T, Wee E, Anuradha $S$ et al. Feasibility and efficiency of a new $22 \mathrm{G}$ core needle: a prospective comparison study. Endoscopy 2013; 45: 792-798

[25] Varadarajulu S, Fraig M, Schmulewitz $N$ et al. Comparison of EUSguided 19-gauge Trucut needle biopsy with EUS-guided fine-needle aspiration. Endoscopy 2004; 36: 397-401

[26] Alatawi A, Beuvon F, Grabar S et al. Comparison of $22 \mathrm{G}$ reverse-beveled versus standard needle for endoscopic ultrasound-guided sampling of solid pancreatic lesions. United European Gastroenterol J 2015; 3: 343-352

[27] Strand DS, Jeffus SK, Sauer BG et al. EUS-guided 22-gauge fine-needle aspiration versus core biopsy needle in the evaluation of solid pancreatic neoplasms. Diagn Cytopathol 2014; 42: 751-758

[28] Bang JY, Hebert-Magee S, Trevino J et al. Randomized trial comparing the 22-gauge aspiration and 22-gauge biopsy needles for EUS-guided sampling of solid pancreatic mass lesions. Gastrointest Endosc 2012; 76: 321-327

[29] Rodrigues-Pinto E, Jalaj S, Grimm IS et al. Impact of EUS-guided fineneedle biopsy sampling with a new core needle on the need for onsite cytopathologic assessment: a preliminary study. Gastrointest Endosc 2016; 84: 1040-1046
[30] Arena M, Eusebi LH, Pellicano R et al. Endoscopic ultrasound core needle for diagnosing of solid pancreatic lesions: is rapid on-site evaluation really necessary? Minerva Med 2017; 108: 547-553

[31] Crinò SF, Manfrin E, Scarpa A et al. EUS-FNB with or without on-site evaluation for the diagnosis of solid pancreatic lesions (FROSENOR): Protocol for a multicenter randomized non-inferiority trial. Dig Liver Dis 2019; 51: 901-906

[32] Aadam AA, Wani S, Amick A et al. A randomized controlled cross-over trial and cost analysis comparing endoscopic ultrasound fine needle aspiration and fine needle biopsy. Endosc Int Open 2016; 4: E497E505

[33] de Moura DTH, McCarty TR, Jirapinyo P et al. Endoscopic ultrasound fine-needle aspiration versus fine-needle biopsy for lymph node diagnosis: a large multicenter comparative analysis. Clin Endosc 2019: doi:10.5946/ce.2019.170 [Epub ahead of print] PubMed PMID: 31794654

[34] Elhanafi S, Mahmud N, Vergara N et al. Comparison of endoscopic ultrasound tissue acquisition methods for genomic analysis of pancreatic cancer. J Gastroenterol Hepatol 2019; 34: 907-913

[35] Eusebi LH, Thorburn D, Toumpanakis C et al. Endoscopic ultrasoundguided fine-needle aspiration vs fine-needle biopsy for the diagnosis of pancreatic neuroendocrine tumors. Endosc Int Open 2019; 7: E1393-E1399

[36] Kurita A, Yasukawa S, Zen Y et al. Comparison of a 22-gauge Franseentip needle with a 20-gauge forward-bevel needle for the diagnosis of type 1 autoimmune pancreatitis: a prospective, randomized, controlled, multicenter study (COMPAS study). Gastrointest Endosc 2020; 91: 373-381 